\title{
Organ culture: the method of choice for preservation of human donor corneas
}

The first successful penetrating keratoplasty in a human was performed as early as 1906 by Zirm. ${ }^{1}$ The tissue was obtained from the eye of a living donor requiring enucleation. Much has changed since then. Advances in surgical instrumentation and techniques and the introduction of antibiotics and corticosteroids in the 1950s significantly improved the success rate of corneal transplantation. Consequently, the demand for donor tissue increased. On the one hand, the supply was enhanced by the possibility of using eyes from human cadavers. ${ }^{2}$ On the other hand, attempts were made to increase the storage time for cadaveric tissue while maintaining the integrity of the endothelial layer. The importance of the corneal endothelium for the maintenance of corneal clarity was convincingly demonstrated by Stocker. ${ }^{3}$ At about the same time in the 1970s two methods for storage of excised human corneoscleral buttons were introduced in the USA and are currently still applied: hypothermic storage ${ }^{45}$ and organ culture preservation..$^{6-8}$

\section{Storage techniques and storage time}

In hypothermic storage corneas are preserved at $4^{\circ} \mathrm{C}$ in tissue culture medium supplemented with antibiotics and with dehydrating agents (dextran, chondroitin sulphate) to prevent corneal swelling. The original $\mathrm{M}-\mathrm{K}$ medium ${ }^{45}$ has been succeeded by solutions such as K-sol, Dexsol, and Likorol potentially allowing a storage time exceeding the 4 days thought to be the maximum for the $\mathrm{M}-\mathrm{K}$ medium. In organ culture preservation corneas are incubated in tissue culture medium supplemented with fetal calf serum, antibiotics, and antimycotics at $30-37^{\circ} \mathrm{C}$. The swelling of the cornea, due to the absence of dehydrating agents in the medium, is reversed shortly before transplantation by placing the cornea, in the first instance, in $\mathrm{M}-\mathrm{K}$ medium at $4^{\circ} \mathrm{C} .{ }^{9}$ Currently the swelling is reversed by transferring the corneas to a culture medium supplemented with dextran $(4-8 \%)$ at room temperature to $37^{\circ} \mathrm{C}$. Because the integrity of the endothelium is better maintained during organ culture ${ }^{6710}$ the storage time of 4 to 5 weeks allowed by organ culture is long compared with the generally accepted period of 3 to 5 days for hypothermic storage. The actual storage time limit for the $4^{\circ} \mathrm{C}$ preservation, however, is not known. Hypothermic storage has been accepted by many eye banks all over the world, while organ culture, strongly promoted by the Eye Bank of Arhus, became the method of choice for eye banks in Europe.

\section{Graft survival}

It is still a point of controversy whether the clinical outcome after grafting of corneas stored by the two different procedures is the same. Bourne et $a l^{11}$ found fewer endothelial cells after grafting on donor corneas stored by organ culture compared with corneas stored in $\mathrm{M}-\mathrm{K}$ medium at $4^{\circ} \mathrm{C}$. The organ culture method used in that study differed, however, from the procedure described earlier ${ }^{8}$ and from the ones used in Europe for organ culture preservation. ${ }^{10}$ One prospective study with paired corneas is available, one cornea stored in $\mathrm{M}-\mathrm{K}$ medium at $4^{\circ} \mathrm{C}$ and the mate in organ culture. Visual acuity, central corneal thickness, and endothelial cell density, 1 to 2 years postoperatively, were similar in age-matched keratoconus recipients. ${ }^{12}$ Retrospective studies comparing the outcome of organ cultured corneas with hypothermically stored corneas demonstrate comparable graft survival and postoperative decline in endothelial cell density ${ }^{13-17}$ Better results with corneas stored by organ culture are also claimed. ${ }^{18}{ }^{19}$ The improvement in graft survival, however, is not ascribed to the storage itself but to extra selections and criteria routinely included in organ culture preservation. Doughman $^{9}$ in 1980 already supposed that the endothelium of corneas stored by organ culture may be of better quality because of the endothelial repair that occurs during this storage. ${ }^{6}$ In addition, overall graft survival may be improved by a reduction of allograft reactions. During organ culture 'passenger' leucocytes are lost ${ }^{20}$ and the donor epithelium becomes hypocellular, ${ }^{10}$ both immunologically modifying the tissue. In the absence of good prospective studies, however, the only scientifically justified conclusion yet is that corneas stored for longer periods by organ culture are at least comparable with those stored at $4^{\circ} \mathrm{C}$ for shorter periods.

\section{Endothelial cell survival}

When Sperling ${ }^{21}$ introduced the organ culture preservation in Europe he combined it with evaluation of the endothelium before and after storage. Differences in endothelial cell loss between individual corneas were found during organ culture. ${ }^{10}$ These differences were supposed to reflect differences in vitality, the organ culture serving as a stress test. Corneas not tolerating long term storage are detected by a significant endothelial cell loss and are discarded. Complete loss of endothelial cells during organ culture was observed and was thought to be related to herpes infection of the donor cornea. ${ }^{22}$ Saggau and Bourne ${ }^{23}$ studied the endothelium of corneas stored for a prolonged period in different solutions (Ksol, CSM medium) at $4^{\circ} \mathrm{C}$. In seven out of 44 corneas no endothelial cells were found after preservation. They concluded that methods are needed to detect corneas not tolerating prolonged storage at $4^{\circ} \mathrm{C}$. Similar experiences by others might explain why the time for hypothermic storage remained 3 to 5 days which is far below the maximal storage time of 16 days suggested by suppliers of storage solutions. These observations also indicate that, irrespective of the storage method used, inspection of the endothelium after intermediate term storage is mandatory to prevent transplantation of corneas of inferior quality. Changes in the endothelium as a result of postmortem time and other variables such as cause of donor death, donor age, circumstances of death, etc, may result in endothelial cell death in the long run.

\section{Tissue evaluation}

The technique introduced for the evaluation of the endothelium with organ culture preservation is staining with trypan blue to test the viability and swelling of the intercellular borders with a hypotonic solution to visualise the endothelium. ${ }^{24}$ Trypan blue staining can be replaced by phase contrast microscopy. ${ }^{25}$ These techniques are well 
suited to endothelial inspection at the end of organ culture preservation because they can be applied irrespective of corneal thickness. Endothelial evaluation is routinely included in the organ culture storage procedure to exclude corneas not tolerating storage. In this way, primary graft failures caused by degenerative changes of the endothelium are also avoided ${ }^{141519}$ or reduced to less than $0.2 \%$ (Dutch collaborative follow up study, unpublished data). In addition, donor age and other variables affecting endothelial cell survival can be ignored thus enhancing the pool of possible donors. The dispatch of tissue with defined endothelial quality was one of the reasons that organ culture storage was preferred in the Netherlands in the early 1980s. Clearness and thickness of a corneoscleral button in vitro depends mainly on the amount of dehydrating agents in the medium, the time from death to storage, and the storage time. It is the ultimate responsibility of the transplant surgeon that the donor corneal tissue is of a satisfactory level. Therefore surgeons prefer to receive donor tissue with a well defined endothelial quality derived from an eye bank where endothelial evaluation of the tissue is an intrinsic part of the procedure. In hypothermic storage specular microscopic control is now used by more than $60 \%$ of the eye banks in the $\mathrm{USA}^{26}$ and in Europe (Directory European Eye Bank Association, 1997). Routine specular microscopy can play an important role in setting higher, more uniform quality standards for tissue acceptance during hypothermic storage. ${ }^{27}$ In addition, its use for tissue from donors above the age of 70 can assess corneas that may otherwise be arbitrarily excluded for transplantation on the basis of age and postmortem time. In this way, the availability of donor corneas can be increased. ${ }^{28}{ }^{29}$ However, this is at the cost of an increasing percentage of corneas, especially from older donors, that will not pass the quality criteria. The discard rate of corneas stored by organ culture is consistently higher compared with that of corneas stored at $4^{\circ} \mathrm{C}$ (Directory European Eye Bank Association, 1997). Assessment of donor corneal endothelium by specular microscopy is able to reduce the risk of primary donor failure to $1.2 \%,{ }^{29}$ which, when compared with the incidence reported with organ cultured corneas, is still relatively high. Because studies linking graft outcome with pretransplant morphometric variables of the endothelium, such as cell size, variation in cell size, cell shape, are missing the debate on the relevance of specular microscopy and endothelial evaluation is still going on. ${ }^{30}$

\section{Microbiological safety}

A major criticism addressed at the organ culture technique is the risk of contamination. The description of the transfer of a fungus ${ }^{31}$ strengthened the doubts about safety. Experience in Europe prove, however, that this criticism is not justified. No case of endophthalmitis due to contamination of the donor cornea has been reported to the Cornea Bank in Amsterdam with over 10000 organ cultured corneas transplanted. Theoretically, the risk in organ culture is lower than in hypothermic storage. Donor eyes are generally contaminated ${ }^{32}$ and every eye bank has to cope with that. Decontamination procedures before enucleation and excision of the corneoscleral button and antibiotics in the storage solution reduce this contamination. Antibiotics and antimycotics are, however, only effective against metabolising micro-organisms, which means that they are much more effective at $30-37^{\circ} \mathrm{C}$ than at $4^{\circ} \mathrm{C}$. During organ culture preservation a mean percentage of $3.5 \%$ of the corneas turn out to be contaminated and are discarded before transplantation (Directory European Eye Bank Association, 1997). In hypothermic storage the scleral rims can only be tested after transplantation and
$12-28 \%$ of them are described to be positive for bacteria and fungi. ${ }^{33}$ So, the risk of transplanting a contaminated cornea is significantly greater in hypothermic storage. Fortunately, the incidence of postoperative keratitis and endophthalmitis caused by microbes transferred with the donor cornea stored at $4^{\circ} \mathrm{C}$ is reported to be low. ${ }^{34}$ Potential growth of bacteria and fungi that may be present on the donor cornea or may be introduced into the culture medium from the environment or by personnel is a well known biohazard for all those working with tissue culture systems. However, by exploiting the vulnerability to microbial contamination of the organ culture system, assessment of the sterility of the donor tissue is possible. One might discuss whether use of the newest antibiotics with the widest spectrums is the best solution to suppress an increasing incidence of postoperative endophthalmitis. In that situation the storage by organ culture might be preferred. In addition, sterility can be better assured for corneas suspected to be at higher risk of contamination-for example, corneas retrieved from donors given mechanical respiratory assistance, having a compromised tear production or blinking reflex, corneas with long death to enucleation times, and corneoscleral buttons removed directly from the donor when there are legislative barriers for enucleation of the cadaveric eye.

\section{Other contaminations}

Another potential source of contamination in the organ culture system stems from components in the media, such as viruses and bacteriophages in commercial fetal calf serum. ${ }^{35}{ }^{36}$ Multiple exposures with these agents must have occurred in human beings for years through the use of vaccines prepared in similar culture cell cultures. In none of these instances has human disease been known to occur from such contaminations. ${ }^{9}$ Nevertheless, caution is warranted when purchasing these kinds of material and the procedures and precautions taken should be described in detail in standard operating procedures. All storage solutions contain foreign materials derived from bacteria (dextran) or animals (chondroitin sulphate). The bovine serum necessary as an additive in the organ culture medium $^{37}$ is nowadays raising concern because of the risk of transfer of Creuztfeld-Jacob-like disease with prions present in the serum. In many European countries the application of bovine products not derived from their own BSE free cattle is prohibited. The use of homologous rather than heterologous serum, which was thought to be theoretically advantageous because of the possibility of modification of the immune graft reaction, might again be worth investigating. Replacement of the serum by chemically better defined and less 'risky' compounds has for years been a major concern for eye banks using organ culture as a storage method.

\section{Conclusion}

Organ culture preservation of human donor corneas does offer advantages when compared with hypothermic storage. With the extended storage time it is possible to (i) schedule operations, (ii) minimise wastage of donor tissue, (iii) facilitate tissue typing and matching, and (iv) control the medium before keratoplasty for microbial contamination. The evaluation of the corneal endothelium offers dispatch of corneas with a well defined endothelial quality assessed after storage and selection of tissue from a large pool of possible donors on endothelial specific criteria. Tissue evaluation is no longer specific for organ culture since the use of the specular microscope has become more and more common during hypothermic storage.

The clinical outcome of both storage methods seem to be comparable. Because of the diverse control possibilities 
mentioned above the organ culture storage procedure is more complicated than the hypothermic storage. According to standards of the European Eye Bank Association (Directory 1997) the organ culture technique is only safe when a post storage endothelial evaluation and a preoperatively sterility control have been performed. Well qualified personnel and advice of microbiological laboratory staff are essential for a proper organ culture procedure but may also be very valuable for hypothermic storage. Hypothermic storage is less complicated but offers fewer possibilities. This all has to be considered before deciding to make organ culture the method of choice for the storage of human donor corneas.

\section{LIESBETH PELS}

Cornea Bank, Netherlands Ophthalmic Research Institute, PO Box 121411100 AC Amsterdam, Netherlands

1 Zirm E. Eine erfolgreiche totale Keratoplastik. Albrecht von Graefes Arch Ophthalmol 1906:64:580-93.

2 Filatov VP. Transplantation of the cornea. Arch Ophthalmol 1935;13:32147.

3 Stocker FW. The endothelium of the cornea and its clinical implications. Trans Am Ophthalmol Soc 1953;51:669-786.

4 McCarey BE, Kaufman HE. Improved corneal storage. Invest Ophthalmol Vis Sci 1974;13:165-73.

5 Bigar F, Kaufman HE, McCarey BE, Binder PS. Improved corneal storage for penetrating keratoplasties in man. Am f Ophthalmol 1975;79:115-20.

6 Doughman DJ, Van Horn DL, Harris JE Miller GE, Lindstrom RL, Good RA. The ultrastructure of human organ-cultured cornea. I Endothelium. Arch Ophthalmol 1974;92:516-23.

7 Summerlin WT, Miller GE, Harris JE, Good RA. The organ-cultured cornea: an in vitro study. Invest Ophthalmol Vis Sci 1973;12:176-80.

8 Doughman DJ, Harris JE, Schmidt KM. Penetrating keratoplasty using $37^{\circ} \mathrm{C}$ organ-cultured cornea. Am Acad Ophthalmol Otol 1976;81:778-93.

9 Doughman DJ. Prolonged donor cornea preservation in organ culture: long-term clinical evaluation. Trans Am Ophthalmol Soc 1980;78:567-628.

10 Pels E, Schuchard Y. In: Brightbill FS, ed. Corneal surgery. 2nd ed. St Louis: Mosby, 1986:93-102.

11 Bourne WM, Doughman DJ, Lindstrom RL, Kolb MJ, Mindrup E, Skelnik $D$. Increased endothelial cell loss after transplantation of corneas preserved by a modified organ culture technique. Ophthalmology 1984;91:285-9.

12 Rijneveld WJ, Beekhuis H, Van Rij G, Rinkel-Van Driel B, Pels E. Clinical comparison of grafts stored in McCarey-Kaufman medium at $4^{\circ} \mathrm{C}$ and in corneal organ culture at $31^{\circ} \mathrm{C}$. Arch Ophthalmol 1992;110:203-5.

13 Bourne WM, Doughman DJ, Lindstrom RL. Organ cultured corneal endothelium in vivo. Arch Ophthalmol 1977;95:1818-9.

14 Doughman DJ, Harris JE, Mindrup E, Lindstrom RL. Prolonged donor cornea preservation in organ culture: long-term clinical evaluation. Cornea 1982;1:7-20.
15 Anderson J, Ehlers N. Corneal transplantation using 4-week banked donor material. Long-term results. Acta Ophthalmol 1987;65:293-9.

16 Redmond RM, Armitage WJ, Whittle J, Moss SJ, Easty DL. Long-term survival of endothelium following transplantation of corneas stored by organ culture. Br F Ophthalmol 1992;76:479-81.

17 Frueh BE, Böhnke M. Corneal grafting of donor tissue preserved for longer than four weeks. Cornea 1994;14:463-6.

18 Völker-Dieben HJ, D’Amaro J, Kok-Van Alphen CC, Pels E. In: Brightbill FS, ed. Corneal surgery. 2nd ed. St Louis: Mosby, 1986:102-13.

19 Böhnke M. The Hamburg system of corneal preservation. Klin Monatsbl Augenheilkd 1991;198:562-71.

20 Pels E, Van der Gaag R. HLA-A, B, C and HLA-DR antigens and dendritic cells in fresh and organ culture preserved corneas. Cornea 1984/1985;3: 231-9.

21 Sperling S. Human corneal endothelium in organ culture. The influence of temperature and medium of incubation. Acta Ophthalmol 1979;57:269-76.

22 Cleator GM, Klapper PE, Dennett C, Sullivan AL, Bonshek RE, Marcyniuk $\mathrm{B}$, et al. Corneal donor infection by herpes simplex virus: herpes simplex virus DNA in donor corneas. Cornea 1994;13:294-304.

23 Saggau DD, Bourne WM. A comparison of two preservation media (CSM and $\mathrm{Ksol}$ ) by scanning electron microscopy of preserved corneal endothelium. Arch Ophthalmol 1989;107:429-32.

24 Sperling S. Endothelial cell density in donor corneas. Acta Ophthalmol 1980; 58:278-82.

25 Böhnke M. Ein neues System zur Lagerung von Spenderhornhäuten. Klin Monatsbl Augenheilkd 1991;198:135-7.

26 Eye Bank Association of America. Statistical Report. Washington DC: Eye Bank Association of America, 1993.

27 Mattern RM, Heck HL, Cavanagh HD. The impact of tissue utilization of screening donor corneas by specular microscopy at the University of Texas Southwestern Medical Center. Cornea 1995;14:562-70.

28 Chu W, Dahl P, O'Neill MJ. Benefits of specular microscopy in evaluating eye donors aged 66 and older. Cornea $1995 ; 14: 568-70$.

29 Wiffen SJ, Nelson LR, Ali AF. Bourne WM. Morphologic assessment of corneal endothelium by specular microscopy in evalution of donor corneas for transplantation. Cornea 1995;14:554-61.

30 Cavanagh HD. Eye banking 1995: danger and oppertunity. Cornea 1995;14: 545-6.

31 Larsen PA, Lindstrom RL, Doughman DJ. Torulopsis glabrata endophthalmitis after keratoplasty with an organ-cultured cornea. Arch Ophthalmol 1978;96:1019-22.

32 Pardos GJ, Gallagher MA. Microbial contamination of donor eyes. A retrospective study. Arch Ophthalmol 1982;100:1611-3.

33 Farrell PL, Fan JT, Smith RE, Trousdale MD. Donor cornea bacterial contamination. Cornea 1991;10:381-6.

34 Leveille AS, McMullan FD, Cavanagh HD. Endophthalmitis following penetrating keratoplasty. Ophthalmology 1983;90:38-9.

35 Kniazeff AJ, Wopschall LJ, Hopps HE, Morris CS. Detection of bovine viruses in fetal bovine serum used in cell culture. In Vitro 1975;11:400-3.

36 Geier MR, Attllah AFM, Merril CB. Characterization of Escherichia coli bacterial viruses in commercial sera. In Vitro 1975;11:55-8.

37 Ayoubi MG, Armitage WJ, Easty DL. Corneal organ-culture: effects of serum and a stabilised form of L-glutamine. Br f Ophthalmol 1996;80:740-4. 